\title{
Associations between plasma micronutrient concentrations and inflammatory cytokine levels among Mexican women with a high prevalence of obesity
}

\author{
G. Zavala ${ }^{1}$, O. P. García ${ }^{1}$, M. C. Caamaño ${ }^{1}$, L. M. Salgado ${ }^{3}$, J. L. Rosado ${ }^{1}$ and K. Z. Long ${ }^{2}$ \\ ${ }^{1}$ Facultad de Ciencias Naturales, Universidad Autónoma de Querétaro, Querétaro, Mexico, ${ }^{2}$ School of Population Health, \\ University of Queensland, Queensland, Australia and ${ }^{3}$ CICATA, IPN, Querétaro, Querétaro, México
}

Obesity has been described as a form of low grade inflammation ${ }^{(1)}$. Inflammatory cytokines such as TNF $\alpha$, IL-1 and IL-6, which are important risk factors for chronic diseases, are elevated in obese individuals. Micronutrient status is associated with obesity and may have an important effect on the inflammatory response ${ }^{(2)}$. The aim of this study was to evaluate the association of micronutrients with chronic inflammation caused by obesity.

A total of 280 women (36.1 7.5 years) from rural communities in Mexico participated in a cross-sectional study. Anthropometric measurements were made on all women. Concentrations of the cytokines IL-1, TNFo, IL- 6 , IL-10 and IL-12 and the micronutrients $\mathrm{Zn}$ and vitamins $\mathrm{A}, \mathrm{C}$ and $\mathrm{E}$ were determined in fasting blood samples. Ordered logistic regression models were used to determine associations between categorised cytokine levels and micronutrients.

Eighty percent of women were either overweight or obese. The risk of higher levels of TNF $\alpha$, IL-6, IL-10 and IL-12 were reduced significantly among women with higher $\mathrm{Zn}$ concentrations. Higher concentrations of vitamin A were associated with reduced risks of higher levels of IL-1 and IL-12. Women with higher vitamin E concentration had increased risks of higher levels of IL-6. No associations were found between vitamin $\mathrm{C}$ concentrations and inflammatory cytokines.

\begin{tabular}{lllll}
\hline & I L-1 $(\mathrm{pg} / \mathrm{ml})$ & IL-6 $(\mathrm{pg} / \mathrm{ml})$ & IL-10 $(\mathrm{pg} / \mathrm{ml})$ & TNF $\alpha(\mathrm{pg} / \mathrm{ml})$ \\
\hline Zn $(\mu \mathrm{g} / \mathrm{ml})$ & $0.81(0.56-1.18)$ & $0.57(0.39-0.84)^{*}$ & $0.63(0.41-0.96)^{*}$ & $0.63(0.41-0.95)^{*}$ \\
Vitamin A $(\mu \mathrm{g} / \mathrm{dl})$ & $0.97(0.95-0.99)^{*}$ & $0.98(0.96-1.00)$ & $0.98(0.95-1.01)$ & $0.63(0.42-0.96)^{*}$ \\
Vitamin C $(\mu \mathrm{g} / \mathrm{ml})$ & $1.04(0.92-1.17)$ & $1.01(0.90-1.13)$ & $1.08(0.95-1.21)$ & $0.98(0.94-0.99)^{*}$ \\
Vitamin E $(\mu \mathrm{g} / \mathrm{ml})$ & $1.04(0.93-1.17)$ & $1.13(1.01-1.27)^{* *}$ & $1.01(0.89-1.15)$ & $1.11(0.98-1.25)$ \\
\hline
\end{tabular}

Values are OR $(95 \% \mathrm{CI})$. OR represent the odds that cytokine levels (categorised into three levels: non-detectable, $<$ median, $>$ median) will be greater among woman with

greater serum micronutrient concentrations. Micronutrient concentrations were included in the model along with $\mathrm{CRP}$ concentrations and age. ${ }^{*} P<0.05, * * P<0.01$.

Higher $\mathrm{Zn}$ and vitamin A concentrations are associated with reduced risks of higher concentration of inflammation markers, while higher concentrations of vitamin E are associated with risk of having higher levels of IL-6 in women with a high prevalence of obesity. It is important to continue addressing the relationship between these micronutrients and the inflammatory response especially among populations that differ in the prevalence of overweight and obesity. Such efforts will establish how specific nutrients may be interacting with adipose tissue to regulate the production of inflammatory cytokines and so modify low-grade inflammation found in obesity.

1. Wellen KE \& Hotamisligil GS (2005) J Clin Invest 115, 1111-1119.

2. García OP, Long KZ \& Rosado JL (2009) Nutr Rev 10, 559-572. 